\title{
Bi-Level Multi-Objective Production Planning Problem with Multi-Choice Parameters: A Fuzzy Goal Programming Algorithm
}

\author{
Murshid Kamal ${ }^{1}$, Srikant Gupta ${ }^{2}\left(\mathbb{D}\right.$, Prasenjit Chatterjee ${ }^{3}$, Dragan Pamucar ${ }^{4, *}$ and \\ Zeljko Stevic ${ }^{5}$ (i) \\ 1 Department of Statistics and Operations Research, Aligarh Muslim University, \\ Aligarh 202002, Uttar Pradesh, India \\ 2 Jaipuria Institute of Management, Jaipur 302022, Rajasthan, India \\ 3 Department of Mechanical Engineering, MCKV Institute of Engineering, Howrah-711204, West Bengal, India \\ 4 Department of logistics, Military academy, University of Defence, Belgrade 11000, Serbia \\ 5 Faculty of Transport and Traffic Engineering Doboj, University of East Sarajevo, \\ Doboj 71000, Bosnia and Herzegovina \\ * Correspondence: dragan.pamucar@va.mod.gov.rs
}

Received: 30 June 2019; Accepted: 16 July 2019; Published: 19 July 2019

\begin{abstract}
This paper deals with the modeling and optimization of a bi-level multi-objective production planning problem, where some of the coefficients of objective functions and parameters of constraints are multi-choice. A general transformation technique based on a binary variable has been used to transform the multi-choices parameters of the problem into their equivalent deterministic form. Finally, two different types of secularization technique have been used to achieve the maximum degree of individually membership goals by minimizing their deviational variables and obtained the most satisfactory solution of the formulated problem. An illustrative real case study of production planning has been discussed and, also compared to validate the efficiency and usefulness of the proposed work.
\end{abstract}

Keywords: production planning; bi-level programming; multi-objective programming; fuzzy goal programming; multi-choice parameter

\section{Introduction}

Bi-level programming (BLP) is considered as the advanced form of mathematical programming. It has been applied to many real-life problems, such as agriculture, production, economic systems, finance, engineering, banking, management sciences, industrial problems, and transportation problems, and so on. Real-life multi-objective problems can be formulated as a bi-level multi-level programming problem in which two decision-makers (DM's)make decisions successively, without affecting the decisions of the others DM's.

BLP is a subclass of the multi-level programming problem which is acknowledged as a mathematical programming problem that is used to solve decentralized planning problems with two DM'sat a hierarchical level. Bi-level multi-objective programming problem (BLMOPP), an apparatus for modeling decentralized decisions, consists of the objectives of the first level decision-maker(FLDM) or leader at its first level and that of the objectives of the second level decision-maker(SLDM) or follower at the second level. The execution of the decision is sequential, from the first level to the second level; each DM independently controls only a set of decision variables and is interested in optimizing their net benefits over a common feasible region. Each DM independently tries to optimize their objective function, in which the decision may be affected by the decisions of the SLDM due to 
the dissatisfaction. BLMOPP is then computationally more complex than the general multi-objective programming problem.

In a mathematical optimization problem, the parameters of the problem are defined or simulated by the DM or experts. The decision-maker fixes the values of these parameters of the mathematical problem. But in many real-life situations, the DM has multiple information available about the parameters of the optimization problem. In such situations, parameters of the problem become a multi-choice type. The decision-maker has the set of multi-choices of the parameters out of which only one choice is to be selected to optimize the problem. This type of mathematical problem is known as a multi-choice programming problem. Such kinds of situations of multiple numbers of choices for a parameter occurs in several decision-making problems. The multi-choice programming problem not only avoids the wastage of resources but also decides on the suitable resources from multiple numbers of resources. The multi-choice programming problems are arising in many areas, such as economics, industry, health care, transportation, agriculture, military, engineering, and technology and many other areas of optimization. Before going to formulate the problem, the following literature has been reviewed, which are discussed in the next section.

\section{Literature Review}

\subsection{Bi-level Programming}

BLP methods are established for solving decentralized decision-making problems at two-levels, the first level is known as leaders or FLDM, and the second one is followers or SLDM. BLP performs the hierarchical structure of decision-making problem, where FLDM solved their problem in separation and then after, delivers the values of their controlling factors. SLDM tries to find their solutions under the guidelines considered by the FLDM in the form of their predominant factors. During the last decade, many researchers studied BLPP deeply, and many methodologies have been developed to solve BLPP. First, [1] used the geometric characterizations and algorithms to get the solution of a particular case of the two-level linear programming problem. Reference [2] proposed a two-person bi-level multi-objective decision-making model and suggested an interactive algorithm to solve the decision-making problem. In this algorithm, they simplified the problem by converting it into separate multi-objective decision-making problems at each level, after that they achieved an optimal solution. In addition, [3] considered the transportation planning and assignment problem as a decentralized two-level integer programming problem and applied an interactive fuzzy programming approach to get a satisfactory solution to the problem. Reference [4] considered bi-level multi-objective programming problems and used the Interactive balance space approach to get an optimal solution.

Some notable work includes [5] which considered a BLPP under integer restrictions and used the concept of tolerance membership function and the branch and bound technique to develop a fuzzy decision model and calculate an optimal solution. Reference [6] presented a fuzzy BLPP. Reference [7] considered multi-objective bi-level decision problems with fuzzy demands and used branch-and-bound approximation algorithm to solve it. Reference [8] considered a decentralized bi-level multi-objective programming problem and proposed a fuzzy goal programming approach to solve it. In this algorithm, they defined the membership functions for all fuzzy goals and objectives at each level, and this algorithm was also extended for solving bi-level multi-objective linear fractional programming problems. Reference [9] proposed $\alpha$-cut and goal programming technique for solving fuzzy linear bi-level multi-objective programming problem. Reference [10] suggested a new particle swarm optimization technique with chaos searching technique to get optimum solutions of the non-linear BLPP and KT condition was used to convert a BLPP into a single objective problem. Reference [11] developed a hybrid model of TOPSIS and fuzzy goal programming algorithm to solve the linear fractional bi-level multi-objective decision-making problem. Reference [12] attempted to solve a bi-level integer multi-objective fractional programming problem with an interactive approach. Reference [13] formulated a chance-constrained algorithm to solve the fractional integer bi-level 
problems. In recent years, [14] considered bi-level multi-objective fractional programming problems and used the Jacobian matrix technique and fuzzy goal programming algorithm to get a satisfactory optimum solution. Reference [15] considered BLPP and suggested an approach for solving the problem by eliminating the terminated constraints, which cause the elimination of cycling to get the solution with infinite steps. Reference [16] developed a hybrid technique with the help of machine learning and optimization concept for solving BLPP.

\subsection{Multi-choice Programming Problem}

In the multi-choice programming problem, the decision-maker is allowed to consider multiple numbers of choices for the parameter of the problem, among all choices, only one is to be selected to optimize the objective function. When [17] first introduced multi-choice, he considered a particular case of mixed integer programming problem with multi-choice type parameters. Later on, $[18,19]$ used binary variables for modeling the multi-choice programming problem, and after that, they also proposed a revised method for multi-choice goal programming model. The most popular multi-choice transformation technique was introduced by [20] and gave the generalized transformation technique for solving multi-choice linear programming problems, where the parameters of the constraint were related to some multi-choices. Some other notable works have been done by [21-26]; all have established different kinds of transformation techniques to select the most suitable choice with the help of the utility function procedure, binary variables technique, interpolating method, Lagrange's interpolating polynomial. Recently, $[27,28]$ formulated a capacitated transportation problem under certain and uncertain environments. These uncertainties in the formulated problem had been tackled by fuzziness, multi-choice, and randomness, respectively.

\subsection{Production Planning}

Production planning is one of the essential activities in supply chain management. Before the beginning of every financial year, many manufacturing companies prepare a production plan. The perfect production plan gives an idea of what quantities of goods are to be produced for each period over the financial year to full fill the demand for each period. The production plan can be executed weekly, monthly, quarterly, or even yearly depending upon the products of the company. Production scheduling is the allocation of available production resources over time to the best satisfy essential criteria, such as quality, delivery time, demand, and supply. A production problem includes a production scheduling problem, machine capacity planning problem, storage, and freight scheduling problems. In the past two decades, technological advancements, international competition, and market dynamics have had a significant impact on the manufacturing industry. Many researchers used different types of mathematical programming techniques for production planning models, such as linear programming [29], mixed integer linear programming [30-32], and goal programming [33-35], and others technique [36-38].

Some notable work includes [39] which proposed a multi-objective model for production planning problem, in which demand and resource availability were specified in the form of grey fuzzy numbers. Reference [40] investigated several distinct types of fuzzy uncertainties in their multiproduct, multiperiod production planning model. Reference [41] established a fuzzy multi-objective model for aggregate production planning problem that contained multiple products and multiple periods in uncertain environments. The proposed model attempts to simultaneously minimize total production cost and minimize total workforce cost under some set of realistic constraints. Reference [42] studied a multi-objective aggregate production planning problem, in which they considered the four criteria, shortage and inventory, overtime and idle time, workforce level, and currency saving in a mid-term planning horizon, respectively. Reference [43] formulated multi-objective integrated production and distribution planning. In this modeling, they considered some of the inputs information about the parameters of the modeling vague. Reference [44] formulated a new model for the production 
distribution problem under uncertain environments and developed an efficient fuzzy goal programming model to get the optimal quantity.

In this paper, we have formulated a production planning problem as a bi-level multi-objective programming problem with a multi-choice interval type parameter. The central purpose of this manuscript is to discuss the four different types of the scenario of multi-choices in objective functions as well as in the constraints. The equivalent crisp form of the multi-choice parameter [45] has been obtained using a general transformation technique of binary variables. The efficient compromise solution of the formulated problem has been obtained by using bi-level and fuzzy goal programming technique, respectively. The solutions obtained from both methods have been compared.

The rest of the paper is planned as follows. Section 3 contains the model formulation of the discussed industrial production planning problem. Section 4 contains the general formulation of BLMOPP. Section 5 contains the formulation BLMOPP with multi-choice interval type. In Section 5, we discuss the transformation technique of multi-choice interval type parameter into their equivalent deterministic form. Section 6 contains the fuzzy goal programming formulation of BLMOPP with a multi-choice interval type parameter. Section 7 contains the numerical case study with the multi-choice decision-making problem solved using LINGO 16.0. Section 8 concludes the paper.

\section{Statement of the Model}

We have considered a production planning problem in which we have chosen different types of machines for the production process, such as a milling machine, lathe, grinder, jig saw, drill press, and band saw. The main objective of every single production business is to make a profit to keep the company running smoothly. It is always advisable for a company to prepare a production plan based on scientific methods to get a clear direction as to how the production process should be carried out. The main objective of this study is to optimize the profit, product liability, quality, and workers' satisfaction. The following input information is essential before formulating the problem, i.e., information about the resources and the available facilities, including production equipment, hours of using the machine for manufacturing product, number of machines available for the production of the item, etc. The following assumptions and limitations which are essential for our industrial planning model are considered as:

- The model has multi-objectives, where we maximize profit, product liability, quality, and workers' satisfaction in the industry.

- The multi-item production model is to be considered.

- One machine cannot perform more than one operation at a time.

- There is no shortage of materials in production.

- Demand should be only for final products.

- Machine and storage capacity cannot exceed the maximum level in any case.

The following notations which have been used during the formulation of the problem:

\section{Nomenclature}

\section{Indices:}

$k$-Index for multi-choices, $k=1,2, \ldots, K$

$j$-Index for the manufactured product, $\mathrm{j}=1,2, \ldots, \mathrm{J}$

$i$-Index for machines $i=1,2, \ldots, I$

$l$-Index for the level, $l=1,2$

$m$-Index for the objectives, $m=1,2, \ldots, M$

\section{Decision Variable:}

$x_{j}$-Manufactured items

\section{Parameters:}


$P_{j}$-Profit related to the product

$L_{j}$-Liability of the product

$Q_{j}$-Quality of the product

$W_{j}$-Workers' satisfaction

$m_{j}$-Milling machine time on $j$ th product

$M$-The total available time of milling machine

$l_{j}$-Lathe time on $j$ th product

L-The total available time of lathe

$g_{j}$-Grinder time on $j$ th product

$G$-The total available time of grinder

$s_{j}$ - Jig saw time on $j$ th product

$S$-The total available time of jig saw

$d_{j}$-Drill press time on $j$ th product

$D$-The total available time of drill press

$b_{j}$-Band saw time on $j$ th product

$B$ - The total available time of band saw

Based on the above assumptions and notations, the mathematical model of the production planning problem is formulated:

The objective function $\mathbf{I}$ is related to maximizing the profit:

Every company wants to remain in business for a longer period, and this can be achieved by only making a profit. In other words, profit is the main oil which drives the wheels of a company, and in a mathematical form, it is represented as:

$$
\operatorname{Max} \mathrm{Z}_{1}=\sum_{j=1}^{3} P_{j} x_{j} .
$$

Objective function II is related to maximizing product reliability:

Every company wants to produce a product that must be reliable for their customers in terms of their longevity. The company's reputation in the market depends upon the reliability of the product produced by the company's during its production run, and in a mathematical form, it is represented as:

$$
\operatorname{Max} Z_{2}=\sum_{j=1}^{3} L_{j} x_{j} .
$$

Objective function III is related to maximizing the quality of the product:

Quality has its importance when it comes to any product of a company. The quality of the product affects the company's reputation. It is very important to uphold the quality of the product and satisfy your customers while retaining their loyalty. Quality products have an important influence on long-term revenue and profit, and it can be written in a mathematical form as:

$$
\operatorname{Max} Z_{3}=\sum_{j=1}^{3} Q_{j} x_{j} .
$$

Objective Function IV is related to maximizing the workers' satisfaction:

Employees influence the business atmosphere through ways in which they cooperate as well as how they respond to customers. If employees behave in a professional-yet-inviting manner, they may be better able to please customers and make the business environment an inviting one. Employee 
satisfaction translates into tangible effects that inevitably lead to a company's increased profitability and success, and in a mathematical form, it is represented as:

$$
\operatorname{Max} Z_{4}=\sum_{j=1}^{3} W_{j} x_{j} .
$$

Constraints

Constraint $\mathbf{I}$ is related to the milling of a product.

$$
\sum_{j=1}^{3} m_{j} x_{j} \leq M .
$$

Constraint II is related to the lathe of a product.

$$
\sum_{j=1}^{3} l_{j} x_{j} \leq L .
$$

Constraint III is related to the grinder of a product.

$$
\sum_{j=1}^{3} g_{j} x_{j} \leq G .
$$

Constraint IV is related to the jigsaw of a product.

$$
\sum_{j=1}^{3} s_{j} x_{j} \leq S .
$$

Constraint $\mathbf{V}$ is related to the drill press of a product.

$$
\sum_{j=1}^{3} d_{j} x_{j} \leq D .
$$

Constraints VI is related to the band saw of a product.

$$
\sum_{j=1}^{3} b_{j} x_{j} \leq B
$$

\section{General Formulation of Bi-Level Multi-Objective Programming Problem (BLMOPP)}

The general form of the bi-level multi-objective problem [46] is given as:

Assume that there are two levels of hierarchy structure with FLDM and SLDM. Let the vector of decision variables $X=\left(x_{1}, x_{2}\right) \in R^{n}$ be subdivided among the two DM. The FLDM has control over the vector $x_{1} \in R^{n_{1}}$, and the SLDM has control over the vector $x_{2} \in R^{n_{2}}$, such that

$$
F_{l}(X): R^{n_{1}} \times R^{n_{2}} \rightarrow R^{n} .
$$

where $n$ are the total number of controllable variables at both the levels, $n_{1}$ and $n_{2}$ are the number of controllable variables in the first and second level, respectively, such that $X_{1}=\left(x_{11}, x_{12, \ldots,}, x_{1 n_{1}}\right)$ and $X_{2}=\left(x_{21}, x_{22, \ldots,}, x_{2 n_{2}}\right)$. So, the BLMOPP of maximization/minimization type may be formulated as follows: 
[Ist level]

$$
\operatorname{Max}_{x_{1}} F_{1}(X)=\underset{x_{1}}{\operatorname{Max}} \operatorname{Min}\left(f_{11}\left(x_{1}, x_{2}\right), f_{12}\left(x_{1}, x_{2}\right), \ldots, f_{1 p_{1}}\left(x_{1}, x_{2}\right)\right)
$$

[IInd level]

$$
\operatorname{Max}_{x_{2}} F_{2}(X)=\underset{x_{2}}{\operatorname{Max}} \operatorname{Min}\left(f_{21}\left(x_{1}, x_{2}\right), f_{22}\left(x_{1}, x_{2}\right), \ldots, f_{2 p_{2}}\left(x_{1}, x_{2}\right)\right)
$$

Subject to

$$
X \in G=\left\{X=\left(x_{1}, x_{2}\right) \in R^{n} \mid A_{1} x_{1}+A_{2} x_{2}\left(\begin{array}{c}
\leq \\
= \\
\geq
\end{array}\right) b, x \geq 0, b \in R^{p}\right\} .
$$

The Equations (2) and (3) represents the objectives of FLDM and SLDM, respectively, while Equation (4) represents the set of general constraints. The decision vector $x$ is divided between two levels, such as $x_{1}$ and $x_{2}$. Let $x_{1}$ be the decision variables control by the FLDM, while $x_{2}$ control by the SLDM. First, FLDM solves their problem by taking into the consideration $x_{1}$ decision vector, and then SLDM solves their problem by reviewing the decision taken by the FLDM and thus finds an efficient vector $x_{2}^{*}$. The value of the FLDM objective function is then calculated as $f_{1}\left(x_{1}, x_{2}^{*}\right)$, provided that the follower solution $x_{2}^{*}$ satisfies the FLDM problem.

\section{BLMOPP with Multi-Choices Interval-Type}

In many real-life problems, there may be a situation where the parameters of the optimization problem are generally not precisely known but can be defined in interval multi-choices. Moreover, instead of a single choice, it may be possible that there are many choices associated with the parameters of the problem. In such a situation, the decision-maker may be confused in selecting the proper choice of the parameters of the problem. To overcome the complexities of the problem, we use the multi-choices interval form. Here we are discussing four different cases with interval-type multi-choices parameters, which follow:

Case I. In this case, we have considered a BLMOPP in which all cost coefficients $C_{l m j}^{k}(k=1,2, \ldots K ; l=1,2 ; m=1,2, \ldots M ; j=1,2, \ldots, J)$ are multi-choice interval type. Then the model is;

$$
\begin{gathered}
\left.\underset{x_{1}}{\operatorname{Max}} Z_{l m}(X)\right)=\sum_{j=1}^{J}\left(C_{l m j}(1), C_{l m j}{ }^{(2)}, \ldots, C_{l m j}{ }^{(k)}\right) x_{j}, \\
\left.\operatorname{Max}_{x_{2}} Z_{l m}(X)\right)=\sum_{j=1}^{J}\left(C_{l m j}{ }^{(1)}, C_{l m j}{ }^{(2)}, \ldots, C_{l m j}{ }^{(k)}\right) x_{j} \\
k=1,2, \ldots, K, l=1,2, m=1,2, \ldots, M ; j=1,2, \ldots, J \\
\sum_{j=1}^{n} a_{i j} x_{j} \leq b_{i} i=1,2, \ldots, I ; j=1,2, \ldots, J \\
x_{j} \geq 0,
\end{gathered}
$$

where $C_{l m j}$ are in the multi-choice interval type from $k=1,2, \ldots, K$.

Case II. In this case, we have considered a BLMOPP where, $a_{i j}(i=12, \ldots, I ; j=1,2, \ldots, J)$ are in the multi-choice interval types. After that, the model is rewritten as: 


$$
\begin{gathered}
\left.\operatorname{Max}_{x_{1}} Z_{l m}(X)\right)=\sum_{j=1}^{J}\left(C_{l m j}\right) x_{j}, \\
\left.\operatorname{Max}_{x_{2}} Z_{l m}(X)\right)=\sum_{j=1}^{J}\left(C_{l m j}\right) x_{j} \\
l=1,2 ; m=1,2, \ldots, M ; j=1,2, \ldots, J \\
\sum_{j=1}^{J}\left(a_{i j}(1), a_{i j}{ }^{(2)}, \ldots, a_{i j}{ }^{(k)}\right) x_{j} \leq\left(b_{i}\right), i=1,2, \ldots, I ; j=1,2, \ldots, J
\end{gathered}
$$

where $a_{i j}$ are in the multi-choice interval type from $k=1,2, \ldots, K$.

Case III. In this case, we have considered a BLMOPP where $b_{i}(i=1,2, \ldots, I)$ are in multi-choice interval type. The model is further rewritten as:

$$
\begin{gathered}
\left.\operatorname{Max}_{x_{1}} Z_{l m}(X)\right)=\sum_{j=1}^{J}\left(C_{l m j}\right) x_{j}, \\
\left.\operatorname{Max}_{x_{2}} Z_{l m}(X)\right)=\sum_{j=1}^{J}\left(C_{l m j}\right) x_{j} \\
l=1,2 ; m=1,2, \ldots, M ; j=1,2, \ldots, J \\
\sum_{j=1}^{J}\left(a_{i j}\right) x_{j} \leq\left(b_{i}{ }^{(1)}, b_{i}{ }^{(2)}, \ldots, b_{i}{ }^{(k)}\right), i=1,2, \ldots, I ; j=1,2, \ldots, J
\end{gathered}
$$

where $b_{i}$ are in the multi-choice interval type from $k=1,2, \ldots, K$.

Case IV. In the final case, we consider a BLMOPP where all the parameters of the problem $\left(C_{l m j}, a_{i j}, b_{i}\right)$ are in the multi-choice interval type. The mathematical model of the problem given by:

$$
\begin{gathered}
\left.\operatorname{Max}_{x_{1}} Z_{l m}(X)\right)=\sum_{j=1}^{J}\left(C_{l m j}{ }^{(1)}, C_{l m j}{ }^{(2)}, \ldots, C_{l m j}{ }^{(k)}\right) x_{j}, \\
\left.\operatorname{Max}_{x_{2}} Z_{l m}(X)\right)=\sum_{j=1}^{J}\left(C_{l m j}{ }^{(1)}, C_{l m j}{ }^{(2)}, \ldots, C_{l m j}{ }^{(k)}\right) x_{j} \\
k=1,2, \ldots, K, l=1,2, m=1,2, \ldots, M ; j=1,2, \ldots, J \\
\sum_{j=1}^{J}\left(a_{i j}{ }^{(1)}, a_{i j}{ }^{(2)}, \ldots, a_{i j}{ }^{(k)}\right) x_{j} \leq\left(b_{i}{ }^{(1)}, b_{i}{ }^{(2)}, \ldots, b_{i}{ }^{(k)}\right), i=1,2, \ldots, I ; j=1,2, \ldots, J
\end{gathered}
$$

where $k,(k=1,2, \ldots, K)$ is the number of alternatives choices for the cost coefficient $C_{l m j}(l=1,2 ; m=1,2, \ldots, M ; j=1,2, \ldots, J)$, number of alternatives choices for the $a_{i j}(i=1,2, \ldots, q ; j=1,2, \ldots, n)$ and number of alternatives choices for them $b_{i}(i=1,2, \ldots, I)$.

In all these four types of cases, some of the parameters of the problem are in the multi-choice interval type. For each multi-choice parameter, the feasible region will be different.

The equivalent deterministic form of the all multi-choices parameter [47] of the above-defined cases is obtained by using the technique which is defined below:

$$
\begin{gathered}
\sum_{j=1}^{n}\left(C_{l m j}{ }^{(1)}, C_{l m j}{ }^{(2)}, \ldots, C_{l m j}{ }^{(k)}\right) x_{j}=\sum_{k=1}^{K}(t e r m)^{k}\left[C_{l m j}^{k^{l}}\left(1-\lambda^{C_{l m j}^{k}}\right)\right]+C_{i m j}^{k^{u}} \lambda^{C_{i m j}^{k}} \\
\sum_{j=1}^{n}\left(a_{i j}{ }^{(1)}, a_{i j}{ }^{(2)}, \ldots, a_{i j}{ }^{(k)}\right) x_{j}=\sum_{k=1}^{K}(\operatorname{term})^{k}\left[a_{i j}^{k^{l}}\left(1-\lambda^{a^{k}}\right)\right]+a_{i j}^{k^{u}} \lambda^{a_{i j}^{k}}, \\
\left(b_{i}{ }^{(1)}, b_{i}{ }^{(2)}, \ldots, b_{i}{ }^{(k)}\right)=\sum_{k=1}^{K}(\operatorname{term})^{k}\left[b_{i}^{k^{l}}\left(1-\lambda^{b_{i}^{k}}\right)\right]+b_{i}^{k^{u}} \lambda^{b_{i}^{k}}, \\
i=1,2, \ldots, I ; j=1,2, \ldots, j ; m=1,2, \ldots, M ; k=1,2, \ldots, K ; l=1,2 .
\end{gathered}
$$

where $(\text { term })^{k}($ for $k=1,2, \ldots, K)$ are the $k$ numbers of terms in functions of the binary variables. 


\section{Fuzzy goal Programming Formulation of BLMOPP with A Multi-Choice Interval Type}

FGP is a power scalarization technique for solving the multi-objective optimization problem. Several contributions have been reported in the literature on FGP approach. Furthermore, bi-level FGP also considered as the flexible scalarization technique for solving a multi-level programming problem.

Below, we have given a step-wise solution procedure for solving the formulated bi-level multi-level industrial planning problem.

Step 1: Formulate the bi-level multi-level production planning problem with multi-choice interval type parameters.

Step 2: As explained in Section 5, convert the multi-choice interval type parameters into their equivalent deterministic form.

Step 3: Solve each objective function as a solitary objective problem using only one objective function at a time. The solutions thus obtained are considered to be ideal solutions for the objectives.

Step 4: Construct the payoff matrix using the ideal solution and then calculate the value of all other objective functions, respectively.

Step 5: Determine the best and worst solution of each objective functions from the payoff matrix.

Step 6: Construct the membership function for each objective as mention below:

First, we construct the membership function for the first level objective functions. Let $G_{l m}, L_{l m}$ be the individual maximum and minimum solution of FLDM and SLDM when calculated in isolation. Then the membership function for the FLDM problem can be formulated as:

$$
\mu_{f_{1 m}}\left(f_{1 m}(X)\right)= \begin{cases}1, & \text { if }\left(f_{1 m}(X)\right) \leq L_{1 m} \\ \frac{\left(f_{1 m}(X)\right)-L_{1 m}}{G_{1 m}-L_{1 m}}, & \text { if } L_{1 m}<\left(f_{1 m}(X)\right)<G_{1 m}, m=1,2, \ldots, M_{1} . \\ 0, & \text { if }\left(f_{1 m}(X)\right) \geq G_{1 m}\end{cases}
$$

Combining the membership function, FGP approach has been used to solve the bi-level multi-level industrial planning problem and, can be written as:

$$
\begin{aligned}
& \operatorname{Min} \sum_{j=1}^{m} w_{1 m}^{+} d_{1 m}^{+} \\
& \text {Subject to } \\
& \frac{\left(f_{1 m}(X)\right)-L_{1 m}}{G_{1 m}-L_{1 m}}+d_{1 m}^{-}-d_{1 m}^{+}=1, m=1,2, \ldots, M_{1} \\
& \sum_{j=1}^{n}\left(a_{i j}{ }^{(1)}, a_{i j}{ }^{(2)}, \ldots, a_{i j}{ }^{(k)}\right) x_{j} \leq\left\{b_{i}{ }^{(1)}, b_{i}{ }^{(2)}, \ldots, b_{i}(k)\right\}, i=1,2, \ldots, I, j=1,2, \ldots, J \\
& x_{j}>0, d_{1 m}^{-} \times d_{1 m}^{+}=0 \text { and } d_{1 m}^{-} d_{1 m}^{+} \geq 0, m=1,2, \ldots, M_{1}
\end{aligned}
$$

where $d_{1 m^{\prime}}^{-} d_{1 m^{\prime}}^{+} m=1,2, \ldots, M_{1}$ represent the under and over deviations from the aspired levels, and $w_{1 m}{ }^{+}, m=1,2, \ldots, M_{1}$ represent the relative importance of attaining the desired levels of the respective fuzzy goals subject to the constraints set for the first level decision making. The value of $w_{1 m}^{+}$is computed as:

$$
w_{1 m}^{+}=\frac{1}{G_{1 m}-L_{1 m}}, m=1,2, \ldots, M_{1} .
$$

Step 7: After getting the optimal solution from the first level, now we have to move to the second level by constructing the membership function for the decision variables and second level objection functions.

Let $t_{r}^{A}$ and $t_{r}^{B}, r=1,2, \ldots, R$ be the supreme negative and positive tolerance values on the decision vector considered by FLDM. Tolerance $t_{r}^{A}$ and $t_{r}^{B}$ are not necessarily the same. The tolerance gives the lower level decision maker an extended feasible region to search for a satisfactory solution. Negative and positive tolerance must be increased as feasibility requirements to give the second level decision-maker a satisfactory solution. 
The linear membership functions for the decision vector of FLDM can be formulated as:

$$
\mu_{2} \equiv \mu_{x_{1}^{r}}\left(X_{1}^{r}\right)= \begin{cases}\frac{X_{1}^{R}-\left(X_{1}^{*^{*}}-t_{r}^{A}\right)}{t_{r}^{A}}, & \text { if } X_{1}^{r^{*}}-t_{r}^{A} \leq X_{1}^{r} \leq X_{1}^{r^{*}} \\ \frac{\left(X_{1}^{r^{*}}+t_{r}^{B}\right)-X_{1}^{r}}{t_{r}^{B}} & \text { if } X_{1}^{r^{*}} \leq X_{1}^{r} \leq X_{1}^{r^{*}}+t_{r}^{B}, r=1,2, \ldots, R . \\ 0 & \text { if otherwise }\end{cases}
$$

The range of $x_{1}^{r}$ can be changed. In FGP approaches, the highest degree of the membership function is one. The defined membership functions equations in (10) and (13) are the flexible membership goals with the aspired levels; one can be represented as:

$$
\mu_{x_{1}^{r}}\left(X_{1}^{r}\right)+d_{l m}^{-}-d_{l m}^{+}=1, r=1,2, \ldots, R
$$

Equation (13) and Equation (14) equivalently written as:

$$
\begin{aligned}
& \frac{X_{1}^{r}-\left(X_{1}^{r^{*}}-t_{r}^{A}\right)}{t_{r}^{A}}+d_{r}^{A-}-d_{r}^{A+}=1, r=1,2, \ldots, R \\
& \frac{\left(X_{1}^{\left.*^{*}+t_{r}^{B}\right)-X_{1}^{r}}\right.}{t_{r}^{B}}+d_{r}^{B-}-d_{r}^{B+}=1, r=1,2, \ldots, R
\end{aligned}
$$

where $d_{r}^{-}=\left(d_{r}^{A-}, d_{r}^{B-}\right), d_{r}^{+}=\left(d_{r}^{A+}, d_{r}^{B+}\right)$, and $d_{l m^{\prime}}^{-} d_{r}^{A-}, d_{r}^{B-}, d_{l m^{\prime}}^{+} d_{r}^{A+}, d_{r}^{B+} \geq 0$ with $d_{l m}^{-} \times d_{l m}^{+}=0, d_{r}^{A-} \times$ $d_{r}^{A+}=0$ and $d_{r}^{B-} \times d_{r}^{B+}=0$ representing the under and over deviation, respectively, from the aspired levels. Furthermore, the membership function for the SLDM problem can be formulated as:

$$
\mu_{f_{2 m}}\left(f_{2 m}(X)\right)= \begin{cases}1, & \text { if }\left(f_{2 m}(X)\right) \leq L_{2 m} \\ \frac{\left(f_{2 m}(X)\right)-L_{2 m}}{G_{2 m}-L_{2 m}}, & \text { if } L_{2 m}<\left(f_{2 m}(X)\right)<G_{2 m}, m=1,2, \ldots, M_{2} . \\ 0, & \text { if }\left(f_{2 m}(X)\right) \geq G_{2 m}\end{cases}
$$

Step 8: In this approach, the over and under deviations are required to minimize the aspiration level of fuzzy goals. Therefore, considering the goals have the same priority in the achievement function, an equivalent fuzzy bi-level multi-objective linear goal programming model can be proposed as:

$$
\operatorname{Min} Z=\sum_{m}^{M_{1}} w_{1 m}^{+} d_{1 m}^{+}+\sum_{m}^{M_{2}} w_{2 m}^{+} d_{2 m}^{+}+\sum_{r=1}^{R}\left[w_{r}^{A}\left(d_{r}^{A-}+d_{r}^{A+}\right)+w_{r}^{B}\left(d_{r}^{B-}+d_{r}^{B+}\right)\right]
$$

\section{Subject to}

$$
\begin{aligned}
& \mu_{f_{1 m}}\left(f_{1 m}(X)\right)+d_{1 m}^{-}-d_{1 m}^{+}=1, m=1,2, \ldots, M_{1}, \\
& \mu_{f_{2 m}}\left(f_{2 m}(X)\right)+d_{2 m}^{-}-d_{2 m}^{+}=1, m=1,2, \ldots, M_{2} \\
& \mu_{x_{1}^{r}}\left(X_{1}^{r}\right)+d_{r}^{-}-d_{r}^{+}=1, r=1,2, \ldots, R, \\
& \sum_{j=1}^{J}\left(a_{i j}(1), a_{i j}\left({ }^{(2)}, \ldots, a_{i j}(k)\right) x_{j} \leq\left\{b_{i}(1), b_{i}{ }^{(2)}, \ldots, b_{i}{ }^{(k)}\right\}, i=1,2, \ldots, I ; j=1,2, \ldots, J\right. \\
& x_{j} \geq 0 \\
& d_{l m}^{-} \times d_{l m}^{+}=0 \text { and } d_{l m}^{-} d_{l m}^{+} \geq 0, d_{r}^{-} \times d_{r}^{+}=0 \text { and } d_{r}^{-}, d_{r}^{+} \geq 0 \\
& l=1,2 ; m=1,2, \ldots, M ; k=1,2, \ldots, K
\end{aligned}
$$

The above problem can be rewritten as: 


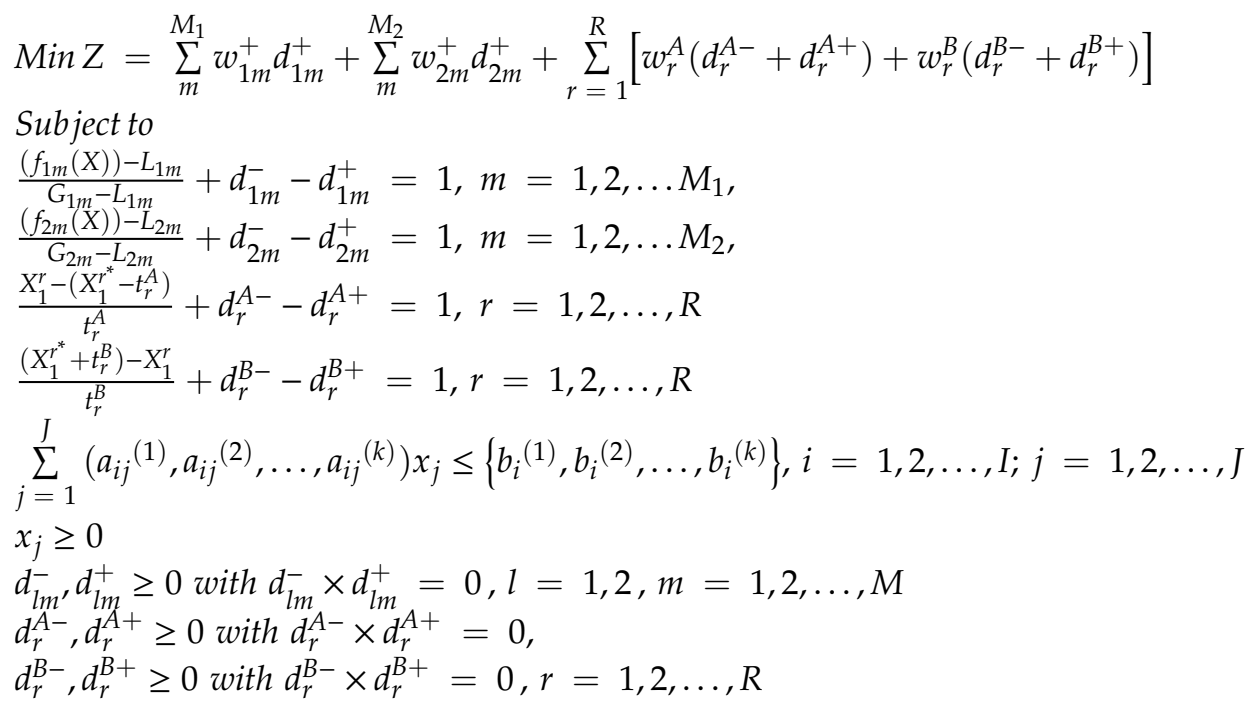

The weighting scheme [47] has been used to assign the values to $w_{l m^{\prime}}^{+}, w_{r}^{A}$, and $w_{r}^{B}$. These values can be determined as:

$$
\begin{gathered}
w_{l m}^{+}=\frac{1}{G_{l m}-L_{l m}}, l=1,2, m=1,2, \ldots, M \\
w_{r}^{A}=\frac{1}{t_{r}^{A}} \text { and } w_{R}^{B}=\frac{1}{t_{r}^{B}}, r=1,2, \ldots, R
\end{gathered}
$$

\section{Numerical Illustration}

Here, we have considered six different types of machines, i.e., milling machine, lathe, grinder, jig saw, drill press, band saw, for industrial production planning problem [48] and formulated it with deterministic parameters. Their capacities are to be dedicated to the production of three products. The current capacity of each machine type is available in hours per week.

Table 1 gives information about the total available time of each machine and the time required by each product.

Table 1. Portfolio of available capacities with deterministic parameter.

\begin{tabular}{ccccc}
\hline \multirow{2}{*}{ Machine Type } & Available Time & \multicolumn{3}{c}{ Machine time } \\
\cline { 3 - 5 } & & Product (1) & Product (2) & Product (3) \\
\hline Milling machine $(m)$ & 1400 & 12 & 17 & 0 \\
\hline Lathe $(l)$ & 1000 & 3 & 9 & 8 \\
\hline Grinder $(g)$ & 1750 & 10 & 13 & 15 \\
\hline Jig saw $(s)$ & 1325 & 6 & 0 & 16 \\
\hline Drill press $(d)$ & 900 & 0 & 12 & 7 \\
\hline Band saw $(b)$ & 1075 & 9.5 & 9.5 & 4 \\
\hline Profit $(P)$ & & 50 & 100 & 17.5 \\
\hline Product liability $(L)$ & 0.72 & 0.85 & 0.78 \\
\hline \multicolumn{2}{c}{ Quality $(Q)$} & 92 & 75 & 50 \\
\hline Workers' satisfaction $(W)$ & 25 & 100 & 75 \\
\hline
\end{tabular}

Using the above information as given in Table 1, the multi-objective industrial programming problem with a deterministic parameter can be formulated as follows: 
[Ist Level]

$$
\operatorname{Max}_{\mathrm{x}_{1} \mathrm{x}_{2}}\left(\begin{array}{ll}
Z_{1}=50 x_{1}+100 x_{2}+17.5 x_{3} & \text { Profit } \\
Z_{2}=0.72 x_{1}+0.85 x_{2}+0.78 x_{3} & \text { Product liability }
\end{array}\right)
$$

[IInd Level]

$$
\operatorname{Max}\left(\begin{array}{ll}
Z_{1}=92 x_{1}+75 x_{2}+50 x_{3} & \text { Quality } \\
Z_{2}=25 x_{1}+100 x_{2}+75 x_{3} & \text { Worker's satisfaction }
\end{array}\right)
$$

Subject to

$$
\begin{array}{cr}
12 x_{1}+17 x_{2} \leq 1400 & \text { (Milling machine) } \\
3 x_{1}+9 x_{2}+8 x_{3} \leq 1000 & \text { (Lathe) } \\
10 x_{1}+13 x_{3}+15 x_{3} \leq 1750 & \text { (Grinder) } \\
6 x_{1}+16 x_{3} \leq 1325 & \text { (Jigsaw) } \\
12 x_{2}+17 x_{3} \leq 900 & \text { (Drill press) } \\
9.5 x_{1}+9.5 x_{2}+4 x_{3} \leq 1075 & \text { (Band saw) } \\
x_{1}, x_{2}, x_{3} \geq 0 &
\end{array}
$$

\begin{tabular}{|c|c|c|c|c|}
\hline \multirow{2}{*}{ Machine Type } & \multirow{2}{*}{ Available Time } & \multicolumn{3}{|c|}{ Machine Time } \\
\hline & & Product (1) & Product (2) & Product (3) \\
\hline Milling machine & $\begin{array}{c}{[1200,1400]} \\
\text { or } \\
{[1400,1600]}\end{array}$ & $\begin{array}{c}{[10,12]} \\
\text { or } \\
{[12,14]}\end{array}$ & $\begin{array}{c}{[15,17]} \\
\text { or } \\
{[17,19]} \\
\text { or } \\
{[19,21]}\end{array}$ & - \\
\hline Lathe & $\begin{array}{c}{[800,1000]} \\
\text { or } \\
{[1000,1200]} \\
\text { or } \\
{[1200,1400]}\end{array}$ & $\begin{array}{c}{[3,5]} \\
\text { or } \\
{[5,4]}\end{array}$ & $\begin{array}{c}{[7,9]} \\
\text { or } \\
{[9,11]} \\
\text { or } \\
{[11,13]}\end{array}$ & $\begin{array}{c}{[6,8]} \\
\text { or } \\
{[8,10]}\end{array}$ \\
\hline Grinder & $\begin{array}{c}{[1650,1750]} \\
\text { or } \\
{[1750,1850]} \\
\text { or } \\
{[1850,1950]} \\
\text { or } \\
{[1950,2050]}\end{array}$ & $\begin{array}{c}{[8,10]} \\
\text { or } \\
{[10,12]} \\
\text { or } \\
{[12,14]}\end{array}$ & $\begin{array}{l}{[13,15]} \\
\text { or } \\
{[15,17]}\end{array}$ & $\begin{array}{c}{[15,17]} \\
\text { or } \\
{[17,19]}\end{array}$ \\
\hline Jig saw & $\begin{array}{c}{[1225,1325]} \\
\text { or } \\
{[1325,1425]}\end{array}$ & $\begin{array}{c}{[4,6]} \\
\text { or } \\
{[6,8]}\end{array}$ & - & $\begin{array}{c}{[12,14]} \\
\text { or } \\
{[14,16]} \\
\text { or } \\
{[16,18]}\end{array}$ \\
\hline Drill press & $\begin{array}{c}700.900] \\
\text { or } \\
{[900,110]} \\
\text { or } \\
{[1100,1300]}\end{array}$ & - & $\begin{array}{c}{[10,12]} \\
\text { or } \\
{[12,14]}\end{array}$ & $\begin{array}{c}5,7] \\
\text { or } \\
{[7,9]} \\
\text { or } \\
{[9,11]}\end{array}$ \\
\hline
\end{tabular}

The above problem formulated with deterministic parameter while there also may be a situation in which this parameter may have multiple choices. Keeping this in mind, we have considered these deterministic parameters as a multi-choice parameter which are given in the Table 2:

Table 2. Portfolio of available capacities with multi-choice parameter. 
Table 2. Cont.

\begin{tabular}{|c|c|c|c|c|}
\hline \multirow{2}{*}{ Machine Type } & \multirow{2}{*}{ Available Time } & \multicolumn{3}{|c|}{ Machine Time } \\
\hline & & Product (1) & Product (2) & Product (3) \\
\hline Band saw & $\begin{array}{c}{[1075,1275]} \\
\text { or } \\
{[1275,1475]} \\
\text { or } \\
{[1475,1675]}\end{array}$ & $\begin{array}{c}{[9.5,11.5]} \\
\text { or } \\
{[11.5,13.5]}\end{array}$ & $\begin{array}{c}{[9.5,11.5]} \\
\text { or } \\
{[11.5,13.5]}\end{array}$ & $\begin{array}{c}{[4,6]} \\
\text { or } \\
{[6,8]} \\
\text { or } \\
{[8,10]} \\
\text { or } \\
{[10,12]}\end{array}$ \\
\hline \multicolumn{2}{|c|}{ Profit } & $\begin{array}{c}{[40,50]} \\
\text { or } \\
{[50,60]} \\
\text { or } \\
{[60,70]}\end{array}$ & $\begin{array}{c}{[90,100]} \\
\text { or } \\
{[100,110]} \\
\text { or } \\
{[110,120]}\end{array}$ & $\begin{array}{c}{[16.5,17.5]} \\
\text { or } \\
{[17.5,18.5]}\end{array}$ \\
\hline \multicolumn{2}{|c|}{ Product liability } & $\begin{array}{c}{[0.70,0.72]} \\
\text { or } \\
{[0.72,0.74]} \\
\text { or } \\
{[0.74,0.76]}\end{array}$ & $\begin{array}{c}{[0.81,0.85]} \\
\text { or } \\
{[0.85,0.89]}\end{array}$ & $\begin{array}{c}{[0.75,0.78]} \\
\text { or } \\
{[0.78,0.81]} \\
\text { or } \\
{[0.81,0.84]} \\
\text { or } \\
{[0.84,0.87]}\end{array}$ \\
\hline \multicolumn{2}{|c|}{ Quality } & $\begin{array}{c}{[82,92]} \\
\text { or } \\
{[92,102]}\end{array}$ & $\begin{array}{c}{[65,75]} \\
\text { or } \\
{[75,85]} \\
\text { or } \\
{[85,95]} \\
\text { or } \\
{[95,105]}\end{array}$ & $\begin{array}{c}{[40,50]} \\
\text { or } \\
{[50,60]} \\
\text { or } \\
{[60,70]}\end{array}$ \\
\hline \multicolumn{2}{|c|}{ Workers' satisfaction } & $\begin{array}{c}{[15,25]} \\
\text { or } \\
{[25,35]}\end{array}$ & $\begin{array}{c}{[90,100]} \\
\text { or } \\
{[100,110]} \\
\text { or } \\
{[110,120]} \\
\text { or } \\
{[120,130]}\end{array}$ & $\begin{array}{c}{[65,75]} \\
\text { or } \\
{[75,85]}\end{array}$ \\
\hline
\end{tabular}

These parameters cannot be used in mathematical programming unless it converts into an equivalent deterministic or crisp form by using the transformation technique as defined in Section 6 . Therefore, we first convert the above multi-choice parameters into equivalent form. After obtaining the equivalent crisp form of the multi-choice parameters, the formulated problem has been solved by using the bi-level fuzzy goal programming technique and furthermore, we had also considered a situation when the decision-maker transformed the bi-level model into multi-objective optimization model without any hierarchy and solved it by using the fuzzy goal programming technique. Using the bi-level fuzzy goal programming technique and fuzzy goal programming technique on the four different cases, i.e., when some or all coefficients of objective functions are in multi-choice type, when some or all coefficients of constraints are in multi-choice type, when some or all coefficients of the right-hand side of the constraints are in multi-choice type, when some or all parameters of the proposed mathematical model are in the multi-choice type, we get the following results, which are given in the Table 3 : 
Table 3. A compromise solution to the problem.

\begin{tabular}{|c|c|c|c|}
\hline \multirow[t]{2}{*}{ Cases } & \multirow[t]{2}{*}{ FGP } & \multicolumn{2}{|c|}{ Bi-Level FGP } \\
\hline & & Ist Level & IInd Level \\
\hline $\mathbf{I}$ & $\begin{array}{c}\mathrm{Z}_{1}=8878.5, \mathrm{Z}_{2}=0.84536 \\
\mathrm{Z}_{3}=10786, \mathrm{Z}_{4}=11185 \\
\mathrm{x}_{1}=28, \mathrm{x}_{2}=56, \mathrm{x}_{3}=41\end{array}$ & $\begin{array}{c}Z_{1}=6079.50, Z_{2}=0.77886 \\
x_{1}=86, x_{2}=7, x_{3}=47\end{array}$ & $\begin{array}{c}\mathrm{Z}_{1}=4929.5, \mathrm{Z}_{2}=0.801329 \\
\mathrm{Z}_{3}=9516, \mathrm{Z}_{4}=8510 \\
\mathrm{x}_{1}=53, \mathrm{x}_{2}=8, \mathrm{x}_{3}=67\end{array}$ \\
\hline II & $\begin{array}{c}\mathrm{Z}_{1}=10,792, \mathrm{Z}_{2}=0.82057 \\
\mathrm{Z}_{3}=10,634, \mathrm{Z}_{4}=12350 \\
\mathrm{x}_{1}=17, \mathrm{x}_{2}=75, \mathrm{x}_{3}=49\end{array}$ & $\begin{array}{c}\mathrm{Z}_{1}=5762.5, \mathrm{Z}_{2}=0.77532 \\
\mathrm{x}_{1}=79, \mathrm{x}_{2}=0, \mathrm{x}_{3}=81\end{array}$ & $\begin{array}{c}\mathrm{Z}_{1}=5772.5, \mathrm{Z}_{2}=0.77611 \\
\mathrm{Z}_{3}=11,624, \mathrm{Z}_{4}=8110 \\
\mathrm{x}_{1}=77, \mathrm{x}_{2}=2, \mathrm{x}_{3}=81\end{array}$ \\
\hline III & $\begin{array}{c}Z_{1}=9575, Z_{2}=0.80512 \\
Z_{3}=10,256, Z_{4}=9335 \\
x_{1}=43, x_{2}=56, x_{3}=28\end{array}$ & $\begin{array}{c}Z_{1}=7437.5, Z_{2}=0.76719 \\
x_{1}=110, x_{2}=5, x_{3}=45\end{array}$ & $\begin{array}{c}Z_{1}=7187.5, Z_{2}=0.76943 \\
Z_{3}=12,589, Z_{4}=6885 \\
x_{1}=102, x_{2}=6, x_{3}=49\end{array}$ \\
\hline IV & $\begin{array}{c}\mathrm{Z}_{1}=11,403, \mathrm{Z}_{2}=0.83419 \\
\mathrm{Z}_{3}=10,929.99 \\
\mathrm{Z}_{4}=10,102.83 \\
\mathrm{x}_{1}=48, \mathrm{x}_{2}=61, \mathrm{x}_{3}=58\end{array}$ & $\begin{array}{c}Z_{1}=6645.50, Z_{2}=0.79027 \\
x_{1}=97, x_{2}=2, x_{3}=83\end{array}$ & $\begin{array}{c}Z_{1}=5697.5, Z_{2}=0.80734 \\
Z_{3}=12,307, Z_{4}=10,000 \\
x_{1}=71, x_{2}=3, x_{3}=95\end{array}$ \\
\hline
\end{tabular}

* FGP = Fuzzy Goal Programming.

The graphical presentation of the results are given in the Figure 1:

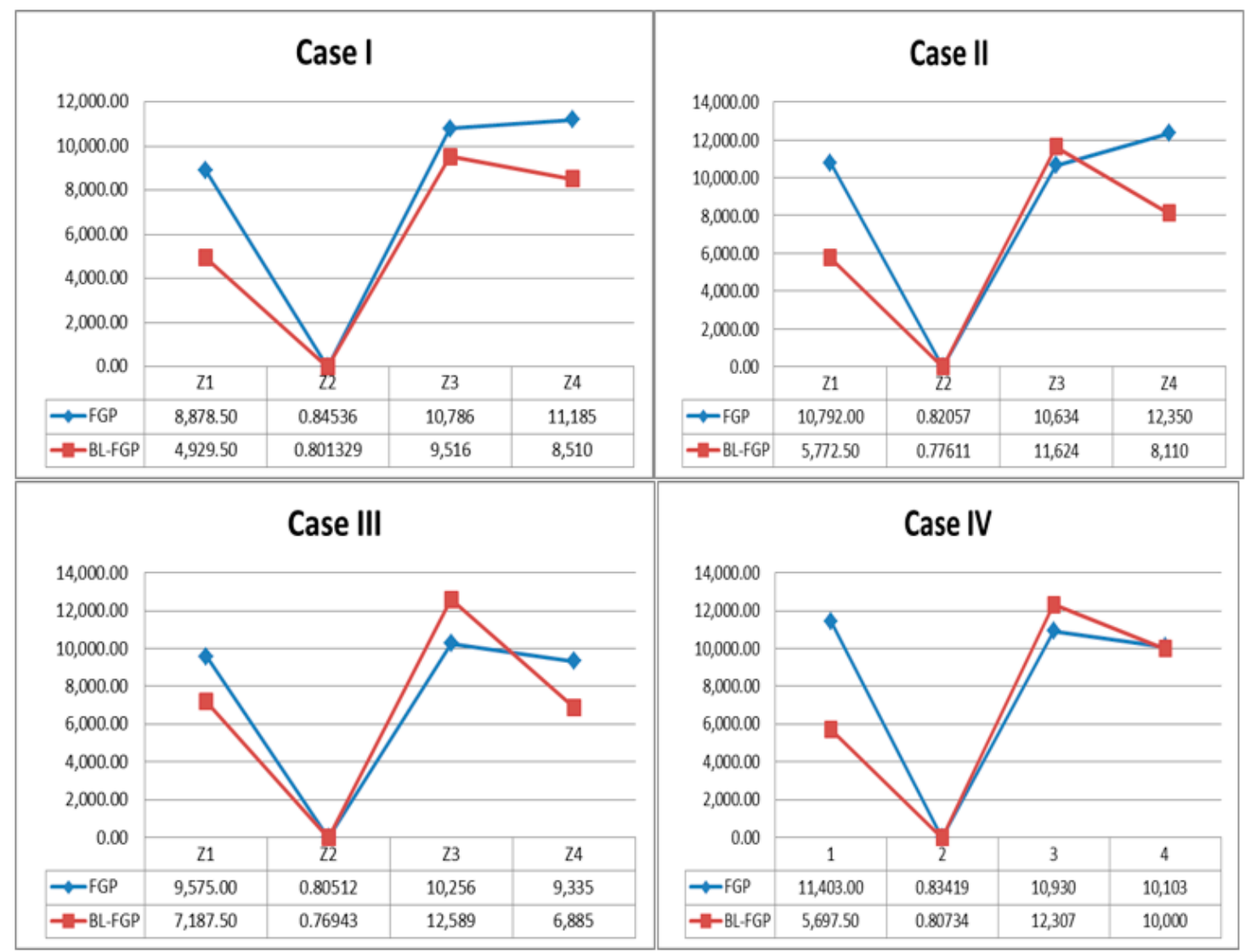

Figure 1. Compromise solution of different cases.

To validate the comparison, we now calculate the trace value of all the cases for the industrial planning problem to know which scalarization technique provides the best efficient solution. The trace value of all the case I, II, III, and IV are given in the Table 4 and Figure 2. 
Table 4. Trace value of the cases.

\begin{tabular}{ccc}
\hline Trace Value & FGP & BL-FGP \\
\hline Case I & $30,850.34$ & $22,956.30$ \\
Case II & $33,776.82$ & $25,507.28$ \\
Case III & $29,166.80$ & $26,662.27$ \\
Case IV & $32,436.65$ & $28,005.31$ \\
\hline
\end{tabular}

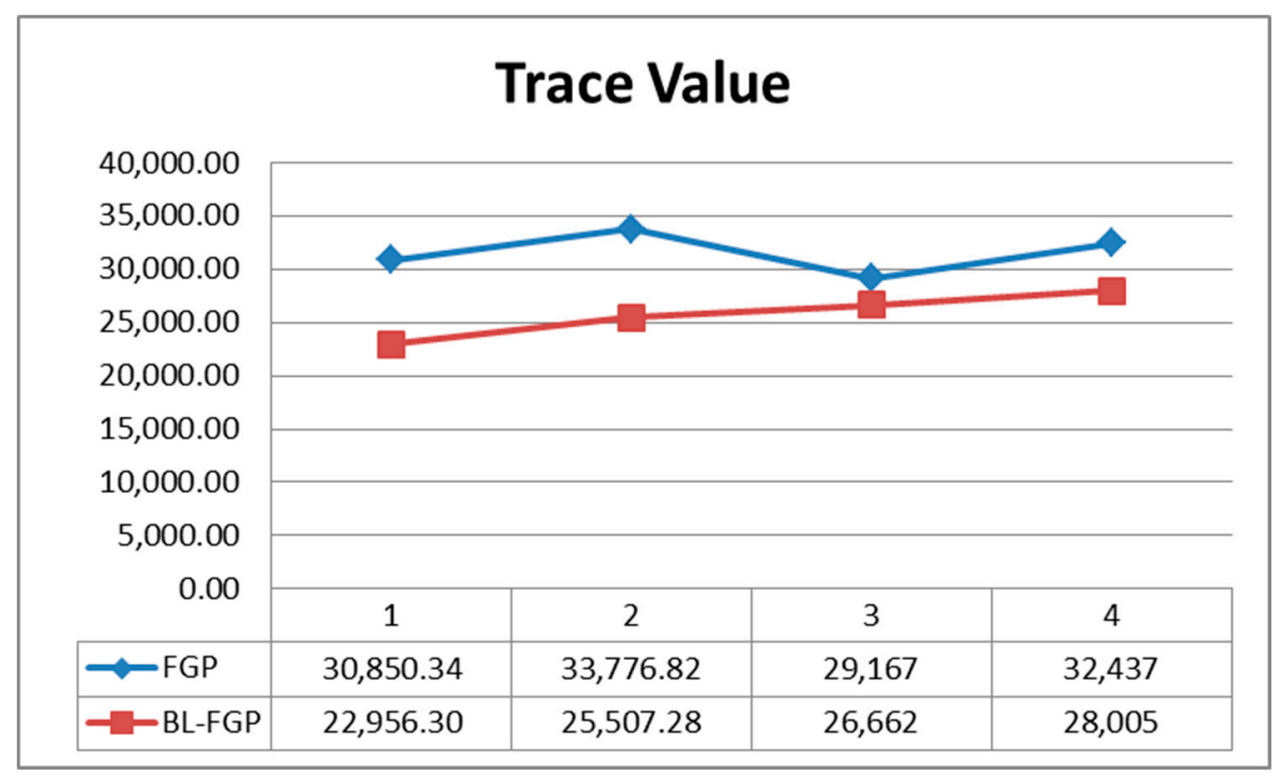

Figure 2. Trace value of different cases.

The obtained results indicate that the fuzzy goal programming technique provides the best efficient solution for the objective functions and decision variables in comparison to bi-level fuzzy goal programming technique. For more clarification purpose, we have used the classical goal programming approach on the formulated problem and found the following solutions, which are given in the Table 5 .

Table 5. Compromise solution.

\begin{tabular}{|c|c|}
\hline Case & Classical Goal Programming \\
\hline I & $\begin{array}{c}Z_{1}=7090.00, Z_{2}=0.867600, Z_{3}=8232.00, Z_{4}=9325.00 \\
x_{1}=21, x_{2}=52, x_{3}=48\end{array}$ \\
\hline II & $\begin{array}{c}Z_{1}=9152.50, Z_{2}=0.924801, Z_{3}=9104.00, Z_{4}=11,325.0 \\
x_{1}=12, x_{2}=78, x_{3}=43\end{array}$ \\
\hline III & $\begin{array}{c}Z_{1}=9027.50, Z_{2}=0.904300, Z_{3}=10,549.00, Z_{4}=9750.00 \\
x_{1}=47, x_{2}=61, x_{3}=33\end{array}$ \\
\hline IV & $\begin{array}{c}Z_{1}=11,894.00, Z_{2}=0.812350, Z_{3}=10,989.00, Z_{4}=11,000.00 \\
x_{1}=42, x_{2}=59, x_{3}=54\end{array}$ \\
\hline
\end{tabular}

\section{Conclusions}

In this paper, we have constructed a new mathematical model for the production planning problem with some realistic assumptions. The constructed model has been formulated as a bi-level multi-level optimization problem with some imprecise information represented by a multi-choice type and transforms into their equivalent deterministic form using the binary variable transformation technique. Furthermore, we have considered four different cases for the formulated problem (some or all coefficient of objective functions are the multi-choice type, some or all coefficient of constraints are in the multi-choice type, some or all coefficient of right-hand side of the constraints are in the 
multi-choice type, some or all parameters of the formulated problem are in the multi-choice type). The bi-level multi-level production planning problem has been turned into a single objective linear programming problem by using the bi-level fuzzy goal programming approach and fuzzy goal programming approach, respectively, to obtain the optimal quantity of the product. All the formulated models have been verified in the production planning numerical case study. Lastly, we conclude that the results obtained by using the fuzzy goal programming approach are found to be efficient when compared to the bi-level fuzzy programming approach.

Author Contributions: Conceptualization, S.G. and M.K.; methodology, S.G.; software, S.G.; validation, S.G., P.C., D.P. and Z.S.; formal analysis, S.G., M.K. and P.C.; investigation, D.P. and Z.S.; resources, P.C., D.P. and Z.S.; data curation, M.K., P.C. and Z.S.; writing—original draft preparation, M.K. and S.G.; writing—review and editing, P.C., D.P. and Z.S.; visualization, S.G.; supervision, P.C.; project administration, P.C.; funding acquisition, D.P..

Funding: This research received no external funding.

Acknowledgments: All authors are deeply thankful to potential reviewers and editors for their valuable suggestions to improve the quality and readability of the manuscript.

Conflicts of Interest: The authors declare no conflict of interest.

\section{References}

1. Bialas, W.F.; Karwan, M.H. Two-level linear programming. Manag. Sci. 1984, 30, 1004-1020. [CrossRef]

2. Shi, X.; Xia, H. Interactive bi-level multi-objective decision making. J. Oper. Res. Soc. 1997, 48, $943-949$. [CrossRef]

3. Sakawa, M.; Nishizaki, I.; Uemura, Y. A decentralized two-level transportation problem in a housing material manufacturer: Interactive fuzzy programming approach. Eur. J. Oper. Res. 2002, 141, 167-185. [CrossRef]

4. Abo-Sinna, M.A.; Baky, I.A. Interactive balance space approach for solving multi-level multi-objective programming problems. Inf. Sci. 2007, 177, 3397-3410. [CrossRef]

5. Emam, O.E. A fuzzy approach for bi-level integer non-linear programming problem. Appl. Math. Comput. 2006, 172, 62-71. [CrossRef]

6. Dempe, S.; Starostina, T. On the Solution of Fuzzy Bilevel Programming Problems. Available online: http://www.optimization-online.org/DB_FILE/2007/09/1778.pdf (accessed on 15 May 2019).

7. Zhang, G.; Lu, J.; Dillon, T. Decentralized multi-objective bilevel decision making with fuzzy demands. Knowl. Based Syst. 2007, 20, 495-507. [CrossRef]

8. Baky, I.A. Fuzzy goal programming algorithm for solving decentralized bi-level multi-objective programming problems. Fuzzy Sets Syst. 2009, 160, 2701-2713. [CrossRef]

9. Gao, Y.; Zhang, G.; Ma, J.; Lu, J. A $\lambda$-cut and goal-programming-based algorithm for fuzzy-linear multiple-objective bilevel optimization. IEEE Trans. Fuzzy Syst. 2010, 18, 1-3. [CrossRef]

10. Wan, Z.; Wang, G.; Sun, B. A hybrid intelligent algorithm by combining particle swarm optimization with chaos searching technique for solving nonlinear bilevel programming problems. Swarm Evol. Comput. 2013, 8, 26-32. [CrossRef]

11. Dey, P.P.; Pramanik, S.; Giri, B.C. TOPSIS approach to linear fractional bi-level MODM problem based on fuzzy goal programming. J. Ind. Eng. Int. 2014, 10, 173-184. [CrossRef]

12. Emam, O.E. Interactive approach to bi-level integer multi-objective fractional programming problem. Appl. Math. Comput. 2013, 223, 17-24. [CrossRef]

13. Saad, O.M.; Emam, O.E. Taylor series approach for solving chance-constrained bi-level integer linear fractional programming problem. Int. J. Math. Arch. 2011, 2, 675-680.

14. Toksarı, M.D.; Bilim, Y. Interactive fuzzy goal programming based on Jacobian matrix to solve decentralized bi-level multi-objective fractional programming problems. Int. J. Fuzzy Syst. 2015, 17, 499-508. [CrossRef]

15. Birla, R.; Agarwal, V.K.; Khan, I.A.; Mishra, V.N. An Alternative Approach for Solving Bi-Level Programming Problems. Am. J. Oper. Res. 2017, 7, 239. [CrossRef]

16. Bagloee, S.A.; Asadi, M.; Sarvi, M.; Patriksson, M. A hybrid machine-learning and optimization method to solve bilevel problems. Expert Syst. Appl. 2018, 95, 142-152. [CrossRef]

17. Healy, W.C., Jr. Multiple choice programming (A procedure for linear programming with zero-one variables). Oper. Res. 1964, 12, 122-138. [CrossRef] 
18. Chang, C.T. Multi-choice goal programming. Omega 2007, 35, 389-396. [CrossRef]

19. Chang, C.T. Revised multi-choice goal programming. Appl. Math. Model. 2008, 32, 2587-2595. [CrossRef]

20. Biswal, M.P.; Acharya, S. Multi-choice multi-objective linear programming problem. J. Interdiscip. Math. 2009, 12, 606-637. [CrossRef]

21. Biswal, M.; Acharya, S. Solving multi-choice linear programming problems by interpolating polynomials. Math. Comput. Model. 2011, 54, 1405-1412. [CrossRef]

22. Roy, S.K.; Mahapatra, D.R.; Biswal, M.P. Multi-choice stochastic transportation problem involving exponential distribution. J. Uncertain Syst. 2012, 6, 200-213.

23. Mahapatra, D.R.; Roy, S.K.; Biswal, M.P. Multichoice stochastic transportation problem involving extreme value distribution. Appl. Math. Model. 2013, 37, 2230-2240. [CrossRef]

24. Roy, S.K. Multi-choice stochastic transportation problem involving Weibull distribution. Int. J. Oper. Res. 2014, 21, 38-58. [CrossRef]

25. Acharya, S.; Biswal, M.P. Solving multi-choice multi-objective transportation problem. Int. J. Math. Oper. Res. 2016, 8, 509-527.

26. Maity, G.; Kumar Roy, S. Solving a multi-objective transportation problem with nonlinear cost and multi-choice demand. Int. J. Manag. Sci. Eng. Manag. 2016, 11, 62-70. [CrossRef]

27. Gupta, S.; Ali, I.; Ahmed, A. Multi-objective capacitated transportation problem with mixed constraint: A case study of certain and uncertain environment. Opsearch 2018, 55, 447-477. [CrossRef]

28. Gupta, S.; Ali, I.; Ahmed, A. Multi-Choice Multi-Objective Capacitated Transportation Problem (A Case Study of Uncertain Demand and Supply). Int. J. Stat. Manag. Syst. 2018, 21, 467-491. [CrossRef]

29. Ebrahimi, H.; Tadic, M. Optimization of dangerous goods transport in urban zone. Decis. Mak. Appl. Manag. Eng. 2018, 1, 131-152. [CrossRef]

30. Vassiliadis, C.G.; Vassiliadou, M.G.; Papageorgiou, L.G.; Pistikopoulos, E.N. Simultaneous maintenance considerations and production planning in multi-purpose plants. In Proceedings of the Reliability and Maintainability Symposium (IEEE), Los Angeles, CA, USA, 24-27 January 2000; pp. 228-233.

31. Christou, I.T.; Lagodimos, A.G.; Lycopoulou, D. Hierarchical production planning for multi-product lines in the beverage industry. Prod. Plan. Control 2007, 18, 367-376. [CrossRef]

32. Sillekens, T.; Koberstein, A.; Suhl, L. Aggregate production planning in the automotive industry with special consideration of workforce flexibility. Int. J. Prod. Res. 2011, 49, 5055-5078. [CrossRef]

33. Rifai, A.K. A note on the structure of the goal-programming model: Assessment and evaluation. Int. J. Oper. Prod. Manag. 1996, 16, 40-49. [CrossRef]

34. Baykasoglu, A.; Gocken, T. Multi-objective aggregate production planning with fuzzy parameters. Adv. Eng. Softw. 2010, 41, 1124-1131. [CrossRef]

35. Leung, S.C.; Chan, S.S. A goal programming model for aggregate production planning with resource utilization constraint. Comput. Ind. Eng. 2009, 56, 1053-1064. [CrossRef]

36. Nikolic, V.; Milovancevic, M.; Petkovic, D.; Jocic, D.; Savic, M. Parameters forecasting of laser welding by the artificial intelligence techniques. Facta Univ. Ser. Mech. Eng. 2018, 16, 193-201. [CrossRef]

37. Anthony, P.; Behnoee, B.; Hassanpour, M.; Pamucar, D. Financial performance evaluation of seven Indian chemical companies. Decis. Mak. Appl. Manag. Eng. 2019. [CrossRef]

38. Roy, J.; Adhikary, K.; Kar, S.; Pamucar, D. A rough strength relational DEMATEL model for analysing the key success factors of hospital service quality. Decis. Mak. Appl. Manag. Eng. 2018, 1, 121-142. [CrossRef]

39. Sadeghi, M.; Hajiagha, S.H.R.; Hashemi, S.S. Fuzzy grey goal programming approach for aggregate production planning. Int. J. Adv. Manuf. Technol. 2013, 64, 1715-1727. [CrossRef]

40. Chen, S.P.; Huang, W.L. Solving fuzzy multiproduct aggregate production planning problems based on extension principle. Int. J. Math. Math. Sci. 2014, 2014, 1-18. [CrossRef]

41. Kalaf, B.A.; Bakar, R.A.; Soon, L.L.; Monsi, M.B.; Bakheet, A.J.K.; Abbas, I.T. A Modified Fuzzy Multi-Objective Linear Programming to Solve Aggregate Production Planning. Int. J. Pure Appl. Math. 2015, 104, 339-352. [CrossRef]

42. Mosadegh, H.; Khakbazan, E.; Salmasnia, A.; Mokhtari, H. A fuzzy multi-objective goal programming model for solving an aggregate production planning problem with uncertainty. Int. J. Inf. Decis. Sci. 2017, 9, 97-115. [CrossRef]

43. Hossain, M.S.; Hossain, M.M. Application of interactive fuzzy goal programming for multi-objective integrated production and distribution planning. Int. J. Process Manag. Benchmark. 2017, 8, 35-58. [CrossRef] 
44. Gupta, S.; Ali, I.; Ahmed, A. Efficient Fuzzy Goal Programming Model for Multi-objective Production Distribution Problem. Int. J. Appl. Comput. Math. 2018, 4, 76-85. [CrossRef]

45. Husain, K.; Rashid, M.; Vitkovic, N.; Mitic, J.; Milovanovic, J.; Stojkovic, M. Geometrical models of mandible fracture and plate implant. Facta Univ. Ser. Mech. Eng. 2018, 16, 369-379. [CrossRef]

46. Gupta, S.; Ali, I.; Ahmed, A. Multi-objective bi-level supply chain network order allocation problem under fuzziness. OPSEARCH 2018, 55, 721-748. [CrossRef]

47. Roy, S.K.; Maity, G. Minimizing cost and time through single objective function in multi-choice interval valued transportation problem. J. Intell. Fuzzy Syst. 2017, 32, 1697-1709. [CrossRef]

48. Zeleny, M. Optimal system design with multiple criteria: De Novo programming approach. Eng. Costs Prod. Econ. 1986, 10, 89-94. [CrossRef]

(C) 2019 by the authors. Licensee MDPI, Basel, Switzerland. This article is an open access article distributed under the terms and conditions of the Creative Commons Attribution (CC BY) license (http://creativecommons.org/licenses/by/4.0/). 